\title{
Runoff modeling of Sebou watershed (Morocco) using SCS curve number method and geographic information system
}

\author{
Khalid Chadli $^{1} \cdot$ Mimoun Kirat $^{1} \cdot$ Abdelhaq Laadoua $^{1} \cdot$ Noureddyne El Harchaoui $^{1}$
}

Received: 29 July 2016/ Accepted: 13 August 2016/Published online: 23 August 2016

(C) Springer International Publishing Switzerland 2016

\begin{abstract}
The Sebou watershed is considered as one of the most important drainage basins in Morocco. This basin had been exposed to frequent flood hazards which were responsible for many damages in several areas of the basin. In the present study, the curve number method was implemented to assess the runoff based on hydrologic modeling method. The use of geographical information system allow us facility in the mapping and geo processing of spatial data for the factor affecting runoff such as land use, hydrologic soil group, digital elevation model and rainfall. The average annual rainfall is $582 \mathrm{~mm}$, and we distinguish two hydrological soil groups with the dominance of group D, the largest land use found in the area is agriculture class. The average curve number is 85 . This high value means a high degree of runoff and a low degree of infiltration. The average annual runoff depth for Sebou watershed is $543.6 \mathrm{~mm}$ which represents $91.5 \%$ of the total annual rainfall. These results revealed that hydrologic model can be used efficiently to support integrated watershed management.
\end{abstract}

Keywords Sebou watershed - Curve number · Runoff · Geographic information system

Khalid Chadli

Chadl_khalid@hotmail.com

1 Department of Geography, Faculty of Letters and Human Sciences, University Moulay Ismail, B.P. 11202, Zitoune, Meknes, Morocco

\section{Introduction}

The coverage of water needs in Morocco has increased in recent years. Water demand increases dramatically, while supply remains fixed with a considerable waste, both in agriculture and in industry, and in the domestic supply. By 2030 , if nothing is done, the deficit will be 5 billion $\mathrm{m}^{3}$.

The water issue is essential, bearing in mind that Morocco has exceeded the period of availability of abundant water. A new era of water scarcity and irregularity of contributions has begun, which makes water management and planning of its use, especially in the medium and long term, essential to ensure the sustainability of water and food security (AHBS 2011).

The Sebou watershed, located in north-west of Morocco, covering an area of about $40.000 \mathrm{~km}^{2}$, representing $6 \%$ of the area of the national territory, it is one of the most important agricultural region and currently contains a total population of about 6 million.

This basin which generally contributes with $30 \%$ of the national potential of surface water resources and $20 \%$ of the ground water resources is drained by the Sebou river that originates in the Middle Atlas and travels about $500 \mathrm{~km}$ before reaching the Atlantic Ocean near Kenitra. The climate prevailing in the whole basin is of type Mediterranean with oceanic influence, and inside the basin the climate becomes more continental. The Sebou basin has an important agricultural and industrial economy which contributes significantly to the national economy.

Many issues and barriers against sustainable development of the Sebou basin are recognized. These problems are due to human activity (erosion, deforestation, uncontrolled urbanization, pollution.), others are more of natural order (spatial and temporal variation in precipitation, droughts, floods etc...). 


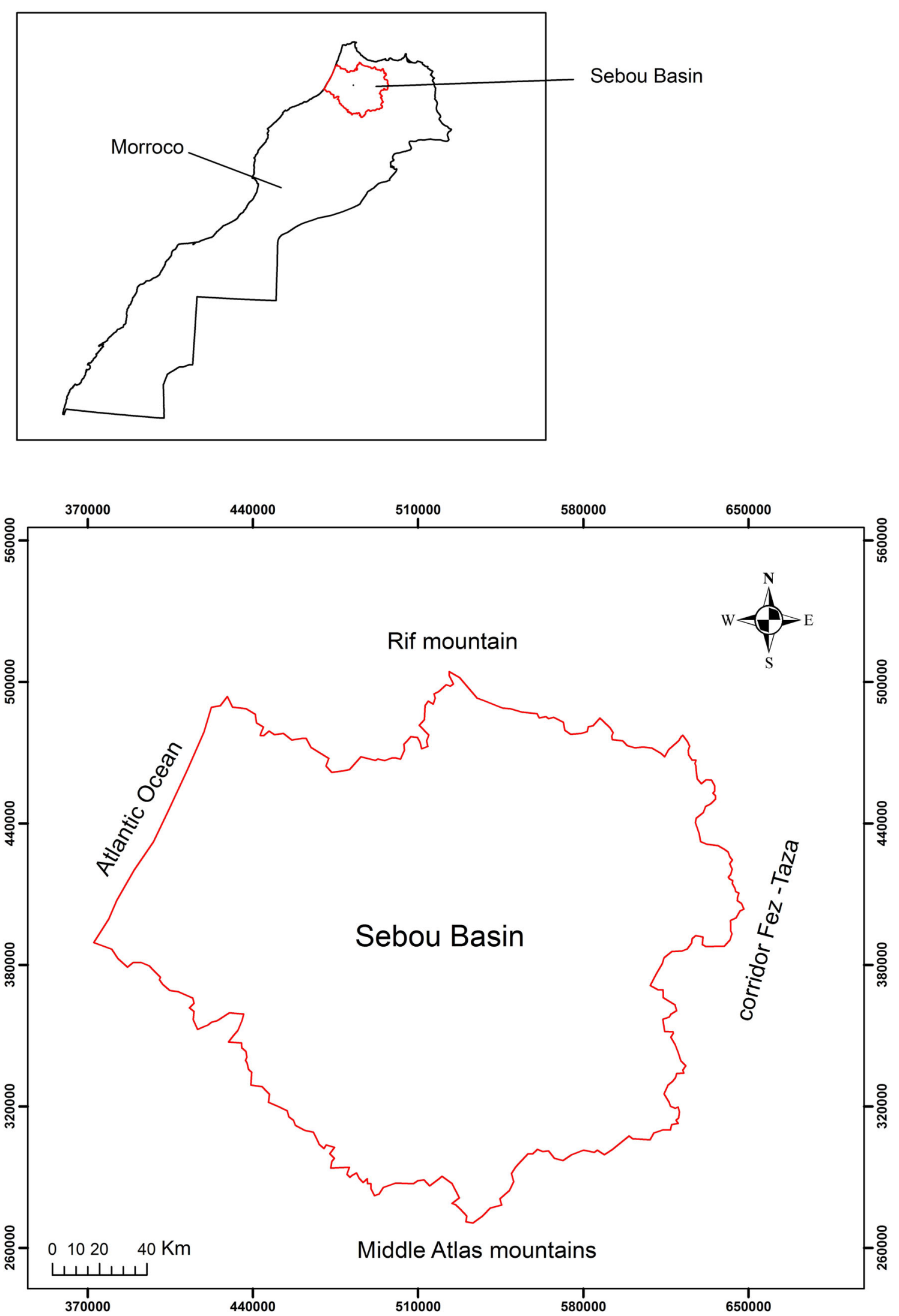

Fig. 1 Study area 


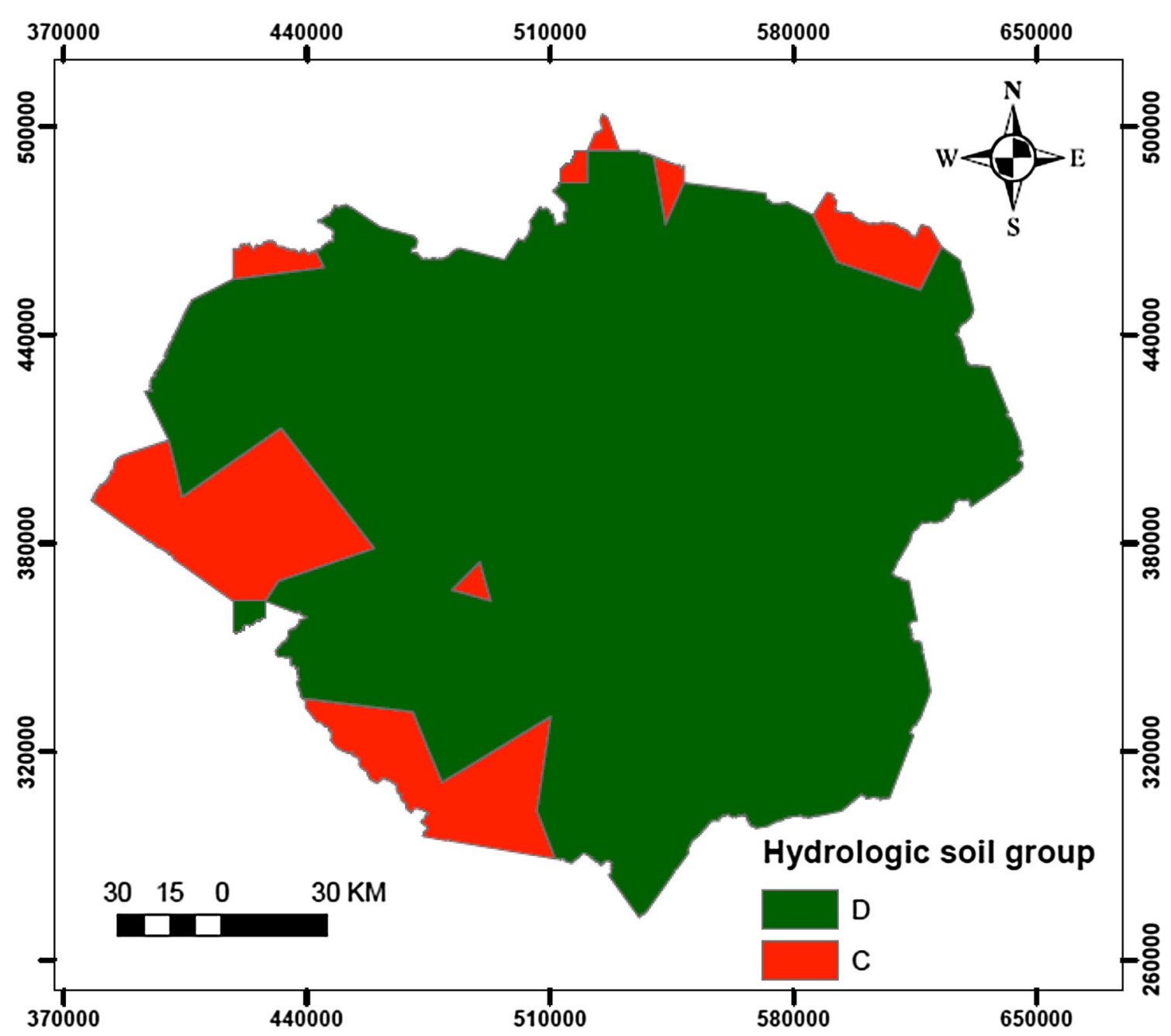

Fig. 2 Hydrologic soil group map

Table 1 Hydrological soil group properties and their distribution in study area

\begin{tabular}{lll}
\hline Hydrological soil group & Description & Distribution (\%) \\
\hline Goupe C & Low infiltration rate & 13.35 \\
Goupe D & Very Low infiltration rate & 86.64 \\
\hline
\end{tabular}

The Sebou Basin (especially in its northern part) is characterized by intense erosion caused by many factors: ground fragility, heavy rainfall intensities, low vegetation cover, human activities (deforestation), steep slopes, unorganized exploitation of forests (Chadli 2016). The consequences of erosion are the most direct loss of land capital and sedimentation of downstream reservoirs.

The Sebou basin has witnessed major flooding in the past, particularly in the Gharb plain. Construction of the dam Al Wahda allowed mitigation of over $90 \%$ of the flood plain. However the 2009 and 2010 floods have demonstrated that the problem still persists.

Runoff is the most important component of water cycle; this coefficient means the flowing off or drainage of precipitation from a catchment area through a surface channel. Its importance lies in the fact that it is used as water resources (maintaining the dams), or in the design drainage network in cities (against flood).

The determination of runoff requires historical record from hydrologic station for the basin, but this data are often not available particularly in developing countries. To solve 


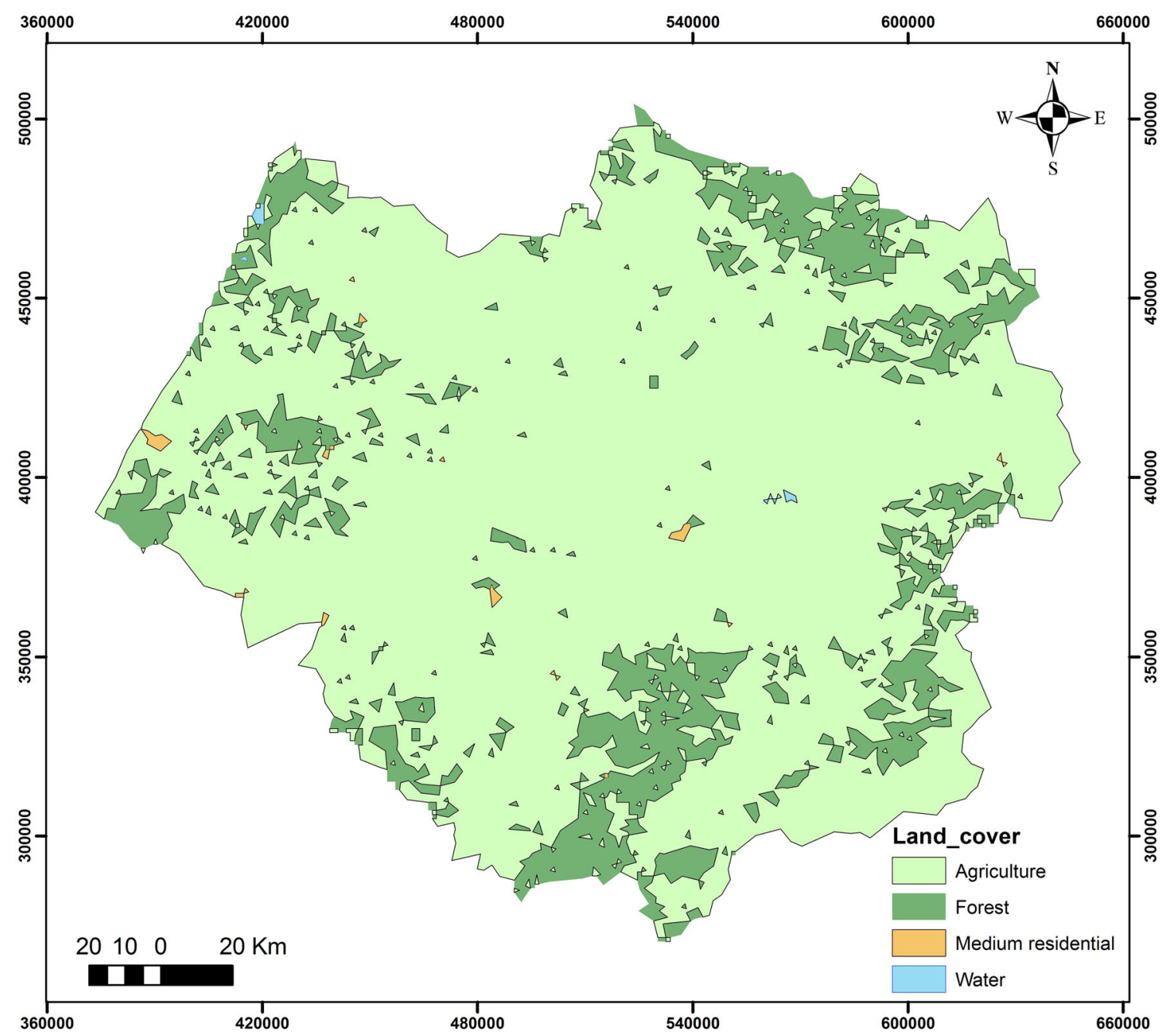

Fig. 3 Land use map

this problem, the hydrologist developed empirical technique from the simplest to the most complex with several variables. The curve number method developed by the USDA Soil Conservation Service (USDA 1986), uses of a series of simple equations with input data like hydrologic soil group, land use type, and precipitation. In addition, the use of the method is facilitated by its implementation in a geographical information system (Al-Jabari et al. 2009; Mohammad and Adamowski 2015; Mahmoud et al. 2014; Taher 2015).

This study aims to evaluate the potential runoff coefficient of Sebou watershed using curve number method integrated with geographic information system.

\section{Description of the study area}

The Sebou watershed (Fig. 1), located in north west of Morocco between parallels $33^{\circ}$ and $35^{\circ}$ north latitude and $4^{\circ} 15^{\prime}$ and $6^{\circ} 35^{\prime}$ west longitude, covers nearly 40.000 $\mathrm{km}^{2}$, and situated between the Rif mountain chain to the north, the Middle Atlas mountains in the south, the corridor Fez-Taza to the east, and Atlantic Ocean to the west.

\section{Data needs and methods}

\section{Soil map}

Soil dataset has been extracted from Digital soil map of the world (FAO 2003) and the hydrological soil group was derived from the database for each soil type.

Soils are classified into four HSG's (A, B, C, and D) depending on their degree of infiltration rate.

Figure 2 and Table 1 indicate the hydrologic group covering study area and their properties, and show dominance of hydrologic soil group D $(86.64 \%)$ that means strong predisposition to runoff. 


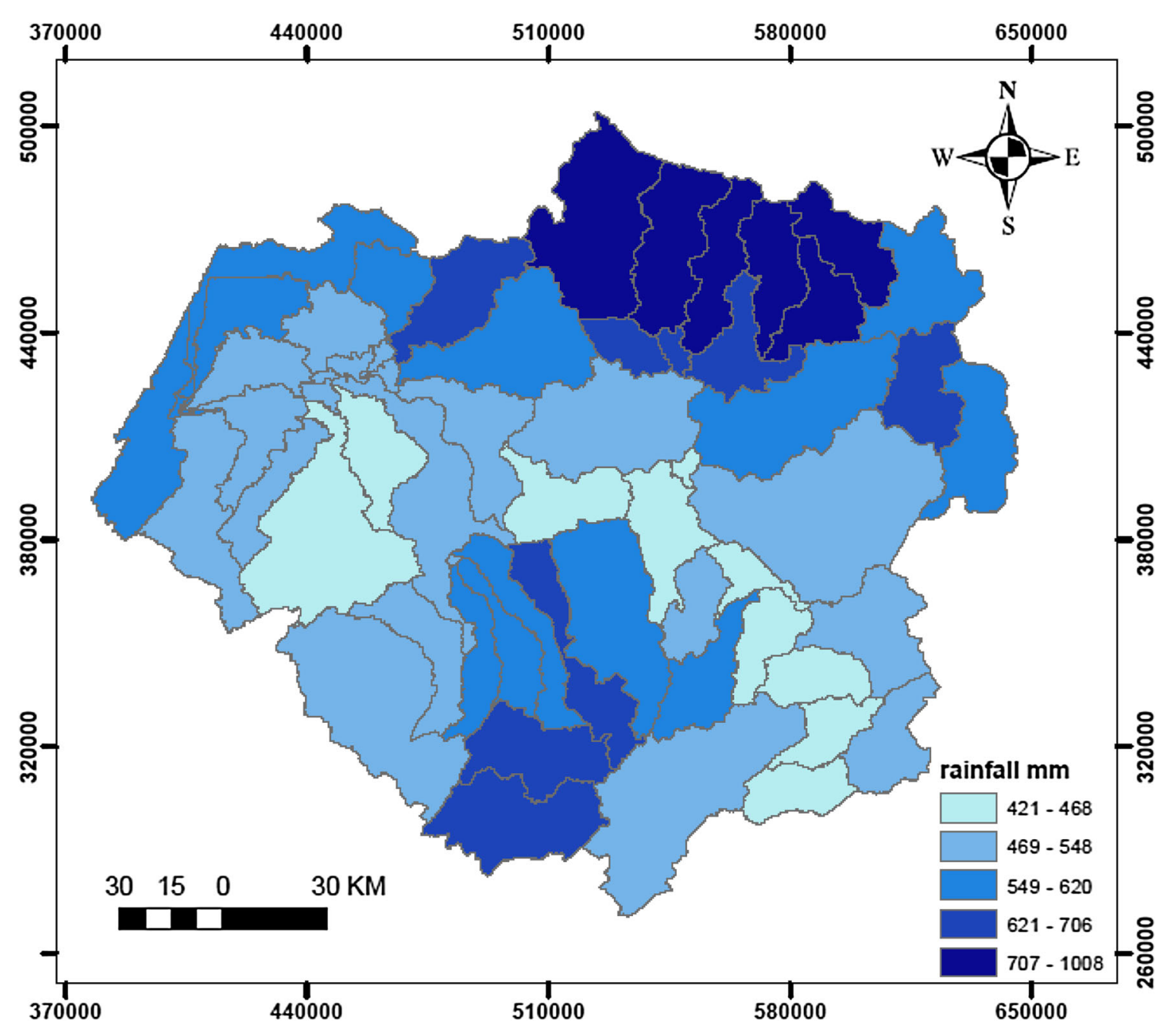

Fig. 4 Average rainfall distribution

\section{Land use map}

Land use map for the study region has been downloaded from Global Land Cover Characterization database (Loveland et al. 2000). The original GLCC was reclassified in four new classes which are: water, medium residential, forest and agriculture.

The dominant land cover types (Fig. 3) are agriculture $(83.83 \%)$, forest $(15.91 \%)$, medium residential $(0.18 \%)$ and water $(0.06 \%)$.

\section{Rainfall data}

Rainfall is the fundamental driving force and pulsar input behind most hydrological processes. The annual rainfall data for the period 1973-2013 have been obtained from the hydraulic agency basin of Sebou (AHBS).
Figure 4 shows that the mean average annual rainfall of Sebou watershed is $582 \mathrm{~mm}$, the maximum is $1008 \mathrm{~mm}$ and the minimum is $421 \mathrm{~mm}$. The rainfall increase from the centre of watershed to the south and to the north (mountainous area).

\section{Digital elevation model}

Digital elevation model of Sebou watershed was collected from global digital elevation data ASTER (Advanced Spaceborne Thermal Emission and Reflection Radiometer) NASA with 30 meters resolution (ASTER GDEM Validation Team 2009). The DEM was processed for delineation of the whole watershed and subbasins. The slope map derived from the topography (Fig. 5) indicates the slopes are steep in the north and the south (mountains areas) and are gentle in the ouest (plain area). 


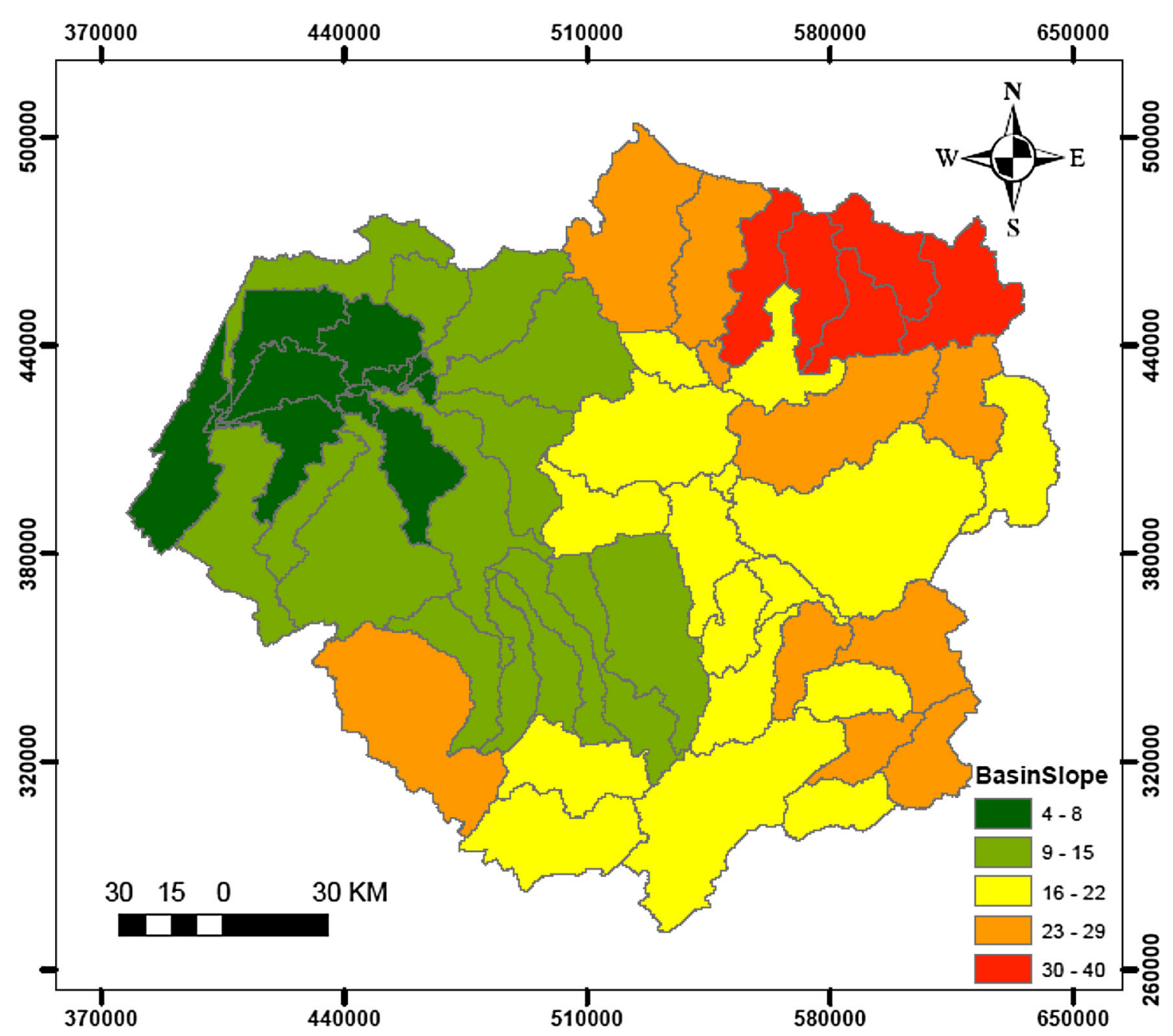

Fig. 5 Slope map

\section{Methods}

To create the $\mathrm{CN}$ grid map, we used a tool in the extension HEC-HMS which is integrated in Arcgis 10.2 interface. This tool requires hydro dem, soil landuse polygons, and curve number lookup. The soil map and land use map were combined and the appropriate $\mathrm{CN}$ value for each polygon of the soil-land use map was assigned using CN Lookup table (Table 2) where their numbers are obtained from SCS TR55 (USDA 1986). The CN Lookup table is like an index can relate the land use and soil group attribute with $\mathrm{CN}$.

$\mathrm{CN}$ is a dimensionless parameter that varies between 0 and 100 . If $\mathrm{CN}$ values tend to a 100 , that indicates impervious surface and their high ability to generate runoff and if values tend to 0 , that implies surface is pervious and low potential of runoff.
Table $2 \mathrm{CN}$ lookup number for each combination landuse hydrologic soil group

\begin{tabular}{lrrrr}
\hline Landuse & \multicolumn{4}{l}{ Hydrologic group } \\
\cline { 2 - 5 } Description & A & B & C & D \\
\hline Water & 100 & 100 & 100 & 100 \\
Medium residential & 57 & 72 & 81 & 86 \\
Forest & 30 & 58 & 71 & 78 \\
Agriculture & 67 & 77 & 83 & 87 \\
\hline
\end{tabular}

The runoff was estimated using SCS curve number method (USDA 1972, 1986). The hydrologic relation between rainfall $(\mathrm{P})$ and runoff $(\mathrm{Q})$ is given by Eqs. (1) and (2): 


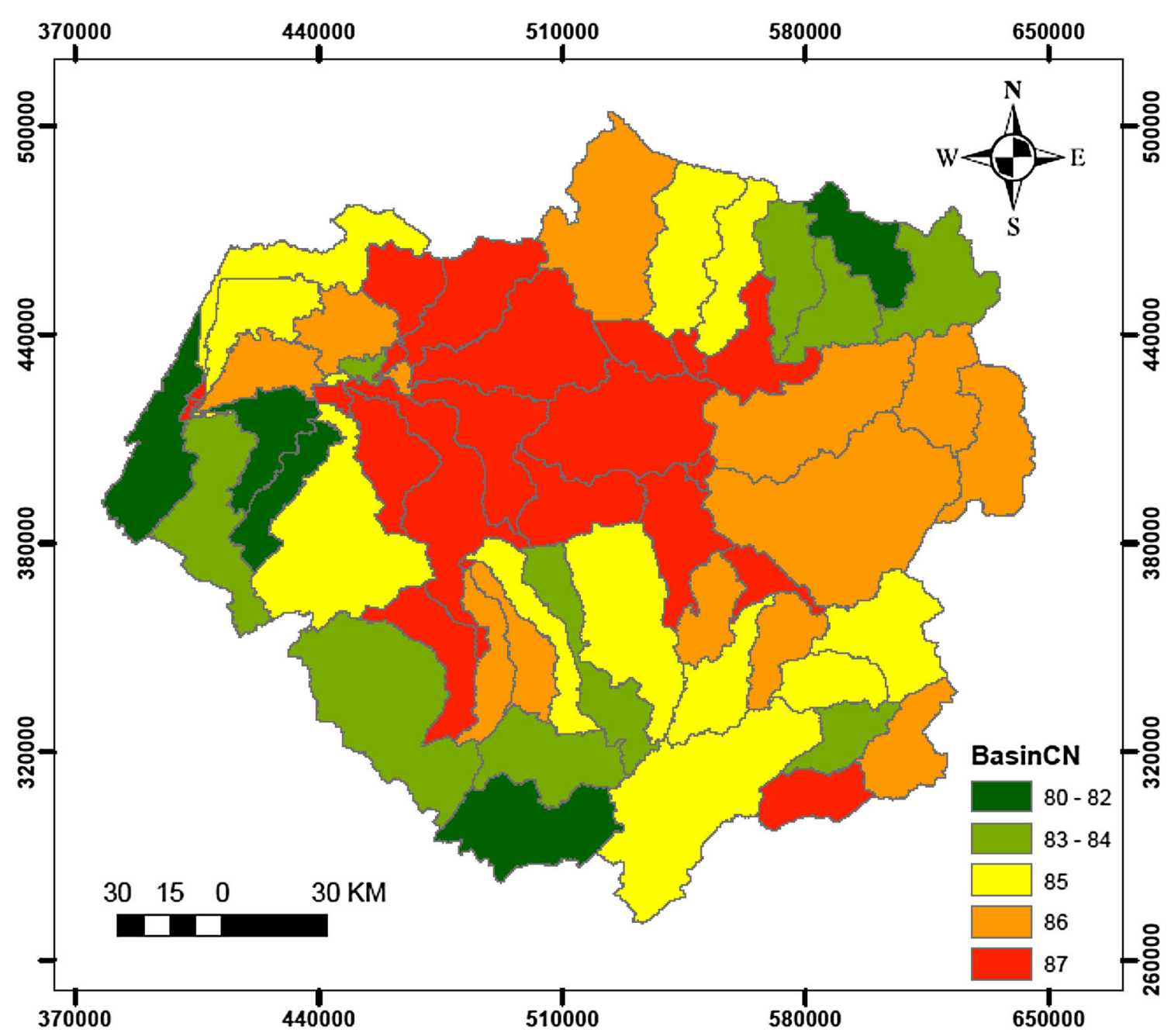

Fig. 6 Curve number map

$\mathrm{Q}=\frac{(P-0.2 S)^{2}}{(P+0.8 S)}$

$\mathrm{S}=\frac{25400}{C N}-254$

where, $\mathrm{Q}$ is the Runoff depth (mm), $\mathrm{S}$ is the maximum potential abstraction (mm), $\mathrm{CN}$ is the Curve Number, $\mathrm{P}$ is the Rainfall depth (mm).

\section{Results and discussion}

The curve number for normal condition (Fig. 6) varies from 80 to 87 and mean is 85 . A high $\mathrm{CN}$ represents a high degree of runoff, and therefore, the risk of flood in these areas is very serious.

The average annual runoff depth (Fig. 7) is equal to $543.6 \mathrm{~mm}$ which represents $91.5 \%$ of the total annual rainfall. The variability in the mean runoff coefficient, which ranges from 378.8 to $951.1 \mathrm{~mm}$, is correlated with the distribution of mean annual precipitation. The mountainous area has the largest runoff (north and the south).

\section{Conclusion}

This study has been carried out to estimate runoff in Sebou watershed using curve number method and geographical information system.

The results show that the dominance of hydrologic soil group D with low permeability and dominant land use is agriculture.

The $\mathrm{CN}$ numbers for Sebou watershed range from 80 to 87 that indicate the majority of surface is impervious and therefore generate high runoff. 


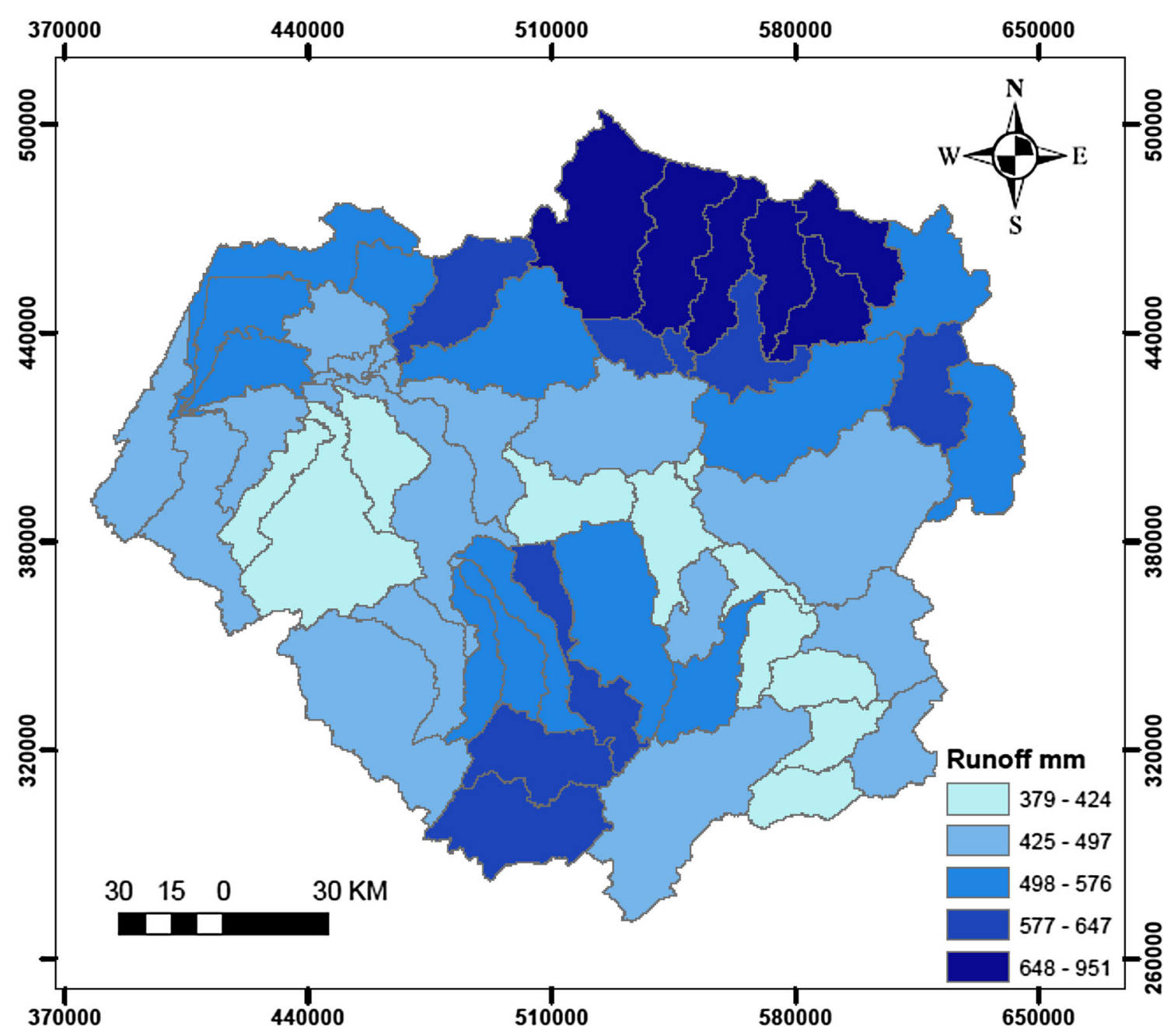

Fig. 7 Annual runoff depth

The distribution in the mean runoff coefficient, which ranges from 378.8 to $951.1 \mathrm{~mm}$, follows the same trend of precipitation.

These results provide basic information for managers to evaluate potential runoff, and then propose solution to mitigate these problems.

\section{References}

AHBS (2011) Plan Directeur d'Aménagement Intégré des Ressources en Eaux du Bassin hydraulique de Sebou. Note de synthèse

ASTER GDEM Validation Team (2009) ASTER Global DEM Validation Summary Report. METI/ERSDAC, NASA/ LPDAAC, USGS/EROS

Al-Jabari S, Sharkh MA, Al-Mimi Z (2009) Estimation of runoff for agricultural watershed using SCS curve number and GIS. In: Thirteenth International Water Technology Conference, IWTC13, Egypt

Chadli K (2016) Estimation of soil loss using RUSLE model for Sebou watershed (Morocco). Model Earth Syst Environ. doi:10. 1007/s40808-016-0105-y
FAO (2003) Digital soil map of the world and derived soil properties. UNESCO, Land and Water Development Division. Rome, Italy: FAO, Land and Water Development Division

Loveland TR, Reed BC, Brown JF, Ohlen DO, Zhu Z, Yang L, Merchant JW (2000) Development of a global land cover characteristics database and IGBP DISCover from $1 \mathrm{~km}$ AVHRR data. Int J Remotes Sens 21(6-7):1303-1330. doi:10.1080/ 014311600210191

Mahmoud SH, Mohammad FS, Alazba AA (2014) Determination of potential runoff coefficient for Al-Baha Region, Saudi Arabia using GIS. Arab J Geosci. doi:10.1007/s12517-014-1303-4

Mohammad FS, Adamowski J (2015) Interfacing the geographic information system, remote sensing, and the soil conservation service-curve number method to estimate curve number and runoff volume in the Asir region of Saudi Arabia. Arab J Geosci. doi:10.1007/s12517-015-1994-1

Taher TM (2015) Integration of GIS Database and SCS-CN Method to Estimate Runoff Volume of Wadis of Intermittent Flow. Arab J Sci Eng. doi:10.1007/s13369-014-1541-5

USDA, Soil Conservation Service (1972) Hydrology. In: National engineering handbook, Section 4, US Govt. Printing office, Washington, DC

USDA, Soil Conservation Service (1986) Urban hydrology for small watersheds. Technical release, no 55 (TR-55). Soil Conservation Service, Washington, DC 